\begin{tabular}{|c|c|}
\hline rist & Malaysian Journal of Social Sciences and Humanities (MJSSH) \\
\hline Malaysian Journal of & Volume 6, Issue 9, September 2021 \\
\hline (MJ-SSH) & e-ISSN : 2504-8562 \\
\hline & $\begin{array}{l}\text { Journal home page: } \\
\text { www.msocialsciences.com }\end{array}$ \\
\hline
\end{tabular}

\title{
Sejarah Budaya Politik Wanita Cina di Semenanjung Malaysia
}

\author{
Nurul Asmaa Ramli' ${ }^{1}$ Kartini Aboo Talib@Khalid1', Hanim Ismail1 ${ }^{1}$,Zainebbeevi Kamalbatcha ${ }^{2}$ \\ ${ }^{1}$ Institut Kajian Etnik, Universiti Kebangsaan Malaysia (UKM) \\ 2Institut Alam Sekitar dan Pembangunan, Universiti Kebangsaan Malaysia (UKM)
}

Correspondence: Nurul Asmaa binti Ramli (tesisphdasmaa@gmail.com)

\begin{abstract}
Abstrak
Budaya politik imigran wanita Cina di Tanah Melayu tidak bersifat statik dan berubah mengikut masa dan keadaan. Hal ini kerana pada awalnya budaya politik imigran wanita Cina adalah berteraskan kepada Tanah Besar China. Ini dapat dilihat melalui penglibatan aktif imigran wanita Cina dalam PKM. PKM di Tanah Melayu mempunyai hubungan yang erat dengan PKM dari Tanah Besar China. PKM di Tanah Melayu bertindak menyalurkan perkembangan politik di Tanah Besar China. Selain itu juga, budaya politik imigran wanita Cina yang berorientasikan kepada Tanah Besar China dapat dilihat melalui penglibatan dalam aktiviti memboikot barangan Jepun, mengutip derma bagi membantu China dalam menentang pencerobohan Jepun di China dengan membentuk China Reliel Fund (Tabung Bantuan Perang Negara China), menyokong Pergerakan Tentera Pembebasan Nasional Nanyang serta menganjurkan aktiviti tunjuk perasaan anti-Jepun. Namun budaya politik imigran wanita Cina telah berubah kepada Tanah Melayu apabila kerajaan China tidak lagi membenarkan rakyat mereka memiliki dua kewarganegaraan. Malah pertambahan bilangan imigran wanita Cina di Tanah Melayu yang semakin meningkat menyebabkan imigran Cina mula berminat menetap di Tanah Melayu. Oleh itu budaya politik imigran Cina yang sebelum ini berteraskan kepada Tanah Besar China telah berubah ke Tanah Melayu. Malah kekejaman PKM, terhadap etnik Cina semasa Tanah Melayu diisytiharkan darurat oleh British telah menyebabkan sokongan imigran wanita Cina terhadap PKM telah semakin berkurang dan beralih kepada MCA.
\end{abstract}

Kata Kunci: budaya politik, imigran Cina, wanita Cina, Tanah Melayu dan Tanah Besar China

\section{History of Women Politics in Malaysia}

\begin{abstract}
The political culture of the Chinese women immigrants in Malaya is not static and changed according to the time and circumstances. This is due to the early days of political culture of the Chinese women immigrants which was based on mainland China. This can be seen through the active participation of Chinese women immigrants in MCP. The MCP in Malaya acted to channel the political developments in mainland China. Apart from that, the political culture of Chinese women immigrants was orientated to mainland China was seen through the participation in the boycott of Japan goods, collecting donations to assist China in countering Japanese aggression in China by forming the China Relief Fund, supporting the Nanyang National Liberation Army Movement as well as organizing anti-Japanese demonstration
\end{abstract}


activities. However, the political culture of Chinese women immigrants changed to Malaya when the government of China decided to no longer allow their citizens to have dual citizenship. In fact, the growth in the number of immigrant women in Malaya which was increasing caused Chinese immigrants to begin being interested to settle down in Malaya. Therefore, the political culture of Chinese immigrants which was grounded to mainland China shifted to Malaya. Besides the brutality of MCP towards the Chinese ethnicity in Malaya during the proclamation of emergency by the British had caused the decrease in support of the Chinese women immigrants towards MCP and shifted to MCA.

Keywords: political culture, Chinese immigrants, Chinese Women, Malaya and Mainland China

\section{Pengenalan}

Kajian ini membincangkan mengenai budaya politik wanita Cina di Semenanjung Malaysia melalui konteks sejarah bermula sebelum negara mencapai kemerdekaan sehinggalah negara mencapai kemerdekaan. Jika ditelusuri migrasi masyarakat Cina di Tanah Melayu bermula seawal tahun 221 S.M lagi. Rentetan berlakunya hubungan perdagangan dan diplomatik antara negara China dengan negeri di Tanah Melayu (Wheatley, 1966, p.88). Hubungan diplomatik awal yang terjalin antara kerajaan di Tanah Melayu dan China adalah disebabkan oleh keperluan komoditi penting yang terdapat di Tanah Melayu disamping untuk mendapatkan perlindungan serta pengiktirafan kerajaan. ${ }^{\mathrm{i}}$ Ini dapat dibuktikan melalui beberapa sumber antaranya ialah catatan sumber bertulis dari Tanah Besar China, hasil penyelidikan

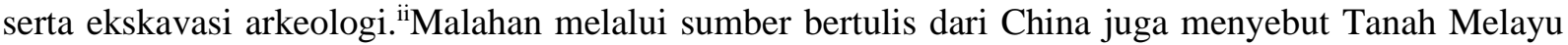
merupakan antara negara yang pernah dilalui sejak 2000 tahun yang lalu. Catatan sumber bertulis ini antaranya adalah melalui manuskrip Ch'ien Han Shu, catatan Hikayat Liang, catatan Liang Shu serta dokumentari Chih Tu Guo Ji. Manuskrip Ch'ien Han Shu telah ditulis pada tahun 80 Masihi dan merupakan antara sumber rujukan awal bertulis mengenai Tanah Melayu. Manakala catatan Hikayat Liang ditulis pada abad ke-3 Masihi yang turut menyentuh mengenai kerajaan awal yang wujud di Tanah Melayu iaitu Tun-sun, Pan-Pan, Langkasuka serta Lin-Yi (Champa). Catatan Liang Shu pula menyentuh mengenai Tan-tan di mana lokasi ini dipercayai berada di Kelantan. Manakala dokumentari Chih Tu Guo Ji telah merakamkan hasil kunjungan Kerajaan Sui pada tahun 607 hingga 610 Masihi ke kerajaan Chihtu yang dipercayai terletak di Tanah Merah (Zuliskandar \& Nik Hassan, 2012, p.171-172).

Jika ditelusuri daripada sumber penyelidikan dan ekskavasi arkeologi, hubungan antara China dan Tanah Melayu dikaitkan dengan hubungan perdagangan. Berdasarkan kepada penemuan artifak arkeologi yang ditemui di tapak-tapak arkeologi terutamanya di pelabuhan entrepot serta pelabuhan pembekal. Data arkeologi ini membuktikan bahawa adanya hubungan perdagangan melalui jumpaan seramik dari China terutamanya daripada Dinasti Tang sehingga Dinasti Ming. Bukti arkeologi ini berdasarkan jumpaan artifak. Namun begitu, artifak sebelum zaman Dinasti Tang tidak dapat dijumpai kerana artifak berupa seramik mula diperdagangkan di kawasan Tanah Melayu semasa zaman Dinasti Tang. Justeru catatan dari China dan jumpaan artifak seramik dari China ialah bukti yang menunjukkan kepentingan Tanah Melayu kepada China dalam menjalinkan hubungan diplomatik dan perdagangan sejak awal kurun Masihi lagi (Nazarudin \& Nasha, 2016: p.21).

Hubungan diplomatik dan perdagangan yang telah terjalin pada awal Masihi antara kerajaan China dan negeri di Tanah Melayu merupakan titik permulaan yang membawa kepada migrasi masyarakat Cina ke Tanah Melayu. Namun begitu, migrasi masyarakat Cina ke Tanah Melayu semakin meningkat semasa pemerintahan British. Pada abad ke-19 dan 20 telah berlaku peningkatan jumlah imigran dari China yang telah mewarnai pelbagai sektor ekonomi di Tanah Melayu dan impak kehadiran ini dikenali sebagai 'zaman Tanah Besar China'. iii Menurut Bonacich dan Cheng, migrasi penduduk lelaki ke Tanah Melayu adalah berdasarkan kepada konsep supply and demand (Bonacich \& Cheng, 1984).Penghijrahan imigran Cina pada awalnya hanya melibatkan golongan lelaki. Namun pada pertengahan abad ke-19, telah berlakunya pertambahan bilangan imigran wanita Cina ke Tanah Melayu. Migrasi skala besar-besaran imigran dari China telah bermula di negeri-negeri Selat iaitu di Singapura, Pulau Pinang dan Melaka. 
Migrasi buruh Cina ke Tanah Melayu adalah melalui pelbagai cara antaranya ialah melalui Sistem Tiket Kredit, Sistem Kangchu dan secara persendirian. Sistem Tiket Kredit, buruh Cina dibiayai secara hutang oleh seorang agen dan mereka akan bekerja dengan agen tersebut sehingga hutang mereka selesai. ${ }^{\text {iv }}$ Melalui sistem Kangchu pula, buruh Cina digalakkan berpindah dari Singapura dan masuk menetap di Johor dan membuka ladang lada hitam dan gambir di bawah pengawasan seorang Kangchu iaitu ketua buruh Cina. Setiap Kangchu bertanggungjawab mengawal, membayar sewa kawasan serta menyelesaikan segala masalah yang dihadapi oleh buruh Cina di bawah pengelolaannya. Pada tahun 1860, seramai 15000 orang buruh Cina telah dibawa masuk ke Johor melalui sistem Kangchu (Novian, 2020, p.8). Manakala buruh yang datang melalui perbelanjaan sendiri tidak terikat kepada mana-mana majikan dan menggunakan pembiayaan sendiri.

\section{Impak Sejarah Migrasi Kepada Budaya Politik Wanita Cina Di Tanah Melayu}

Berlatarkan awal kurun awal kurun ke-19, penglibatan wanita Cina dalam struktur ekonomi di Tanah Melayu adalah tidak ketara jika dibandingkan dengan kaum lelaki Cina. Fenomena ini, rentetan kurangnya bilangan wanita di Tanah Melayu pada awal kurun ke-19 (Dancz, 1987, p.34). Pelbagai faktor yang menyebabkan bilangan migrasi wanita pada sebelum pertengahan abad ke-19 adalah sedikit. Antaranya ialah kos tambang wanita yang mahal berbanding lelaki kerana dasar pemerintah Tanah Besar China yang tidak membenarkan migrasi dalam kalangan wanita, kos penginapan yang mahal, penginapan yang disediakan oleh majikan tidak kondusif, serta tanggungjawab wanita dalam kerangka budaya. Natijahnya, aktiviti pelacuran telah berkembang pesat di Tanah Melayu pada awal kurun ke-18. Hal ini rentetan daripada permintaan yang tinggi ke atas pelacur, ditambah dengan kepesatan aktiviti pemerdangangan wanita dan kanak-kanak di Tanah Besar China. Aktiviti yang berlatarkan kepada pelacuran ini turut didukung oleh British pada awalnya, kerana premis ini telah mengundang keuntungan hasil kutipan cukai.

Namun pada penghujung kurun ke-18 telah berlaku peningkatan migrasi wanita di Tanah Melayu. Berakar dari pelbagai faktor penarik dan penolak antaranya ialah keadaan anarki yang telah dicetuskan dari peperangan antara kerajaan China dan British sehingga mewujudkan Perang Candu Pertama dan Kedua dan termeterainya perjanjian Perjanjian Nanjing serta Perjanjian Tianjin. Perjanjian yang dikatakan merugikan China ini telah menimbulkan bibit ketidakpuasan hati dalam kalangan rakyat Tanah Besar China yang telah diterjemahkan melalui Pemberontakan Taiping (1850-1864) dan Boxer (18991901). Natijahnya rakyat hidup dalam kesusahan, aktiviti ekonomi tidak dapat dijalankan malahan keadaan ini menjadi lebih parah rentetan daripada bencana alam yang berlaku. Sumber bekalan makanan tidak dapat menampung bilangan penduduk China yang ramai. Oleh itu wanita juga terpaksa bermigrasi ke luar negara untuk mencari rezeki.

Selain itu juga, antara faktor lain yang meningkatkan bilangan migrasi wanita adalah, industri sutera yang menjadi lubuk pekerjaan bagi wanita Cina telah jatuh, pembentukan The Immigration Restriction Ordinance Of $1928^{v i}$ dan The Aliens Ordinance of 1933 yang telah mengehadkan bilangan imigran lelaki, peluang pekerjaan yang telah ditawarkan di Tanah Melayu, serta keadaan aman di Tanah Melayu. Pada awalnya, kebanyakan imigran Cina datang ke Tanah Melayu hanya ingin menjana pendapatan dan mereka berniat untuk kembali ke Tanah Besar China. Oleh itu imigran Cina yang bermigrasi ini di kenal sebagai Zhongguo Ren (中国人) yang memegang kerakyatan dari Tanah Besar China serta Huaqio (夏 威夷花人) yang menumpang sementara di luar negara China dan ingin kembali ke negara China. ${ }^{\text {vi }}$

Oleh sebab itulah, budaya politik masyarakat Cina di Tanah Melayu adalah berteraskan kepada Tanah Besar China. Hal ini dapat dilihat melalui usaha yang telah ditonjolkan oleh imigran Cina di Tanah Melayu melalui pelbagai tindakan yang mendukung Tanah Besar China, merangkumi pembentukan Malayan Anti-Imperialist League, aktiviti memboikot barangan Jcpun, mengutip derma bagi membantu China dalam mencntang pencerobohan Jepun di China dengan membentuk China Reliel Fund (Tabung Bantuan Perang Negara China), menyokong Pergerakan Tentera Pembebasan Nasional Nanyang (Nanyang National Salvation Movement) serta menganjurkan aktiviti tunjuk perasaan anti-Jepun (Ho, 2009, p.111). Tindakan ini juga turut di sertai bukan sahaja dalam kalangan imigran lelaki Cina malahan 
imigran wanita Cina. Hal ini dapat dilihat melalui pergerakan anti-Jepun di Tanah Melayu, di mana golongan pekerja wanita dan intelektual wanita Cina telah bersatu dan melaungkan slogan 'kekuatan atau kejatuhan negara turut melibatkan wanita'. Pergerakan ini adalah sebagai tanda sokongan kepada saudara-mara mereka yang telah menderita akibat pencerobohan Jepun di Tanah Besar China (Fan, 2005, p.264-272).

Budaya politik imigran Cina termasuklah imigran wanita Cina di Tanah Melayu ini, telah dipengaruhi oleh pelbagai medium antaranya ialah melalui sistem pendidikan, akhbar, parti politik berhaluan kiri

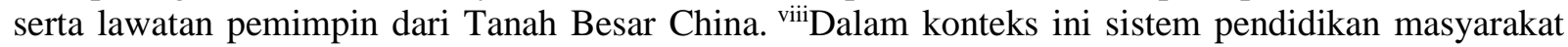
Cina di Tanah Melayu adalah berteraskan kepada Tanah Besar China ${ }^{\text {ix }}$ Pada awalnya, anak perempuan tidak digalakkan ke sekolah namun perkembangan gerakan feminisme di Tanah Besar China turut memberikan kesan kepada perkembangan wanita di Tanah Melayu di mana, berlaku peningkatan dalam bilangan pelajar perempuan ke sekolah. Pencerobohan Jepun di Tanah Besar China, seolah-olah memberikan tamparan kepada mereka mengenai kepentingan menuntut ilmu. Fenomena ini telah mula menyedarkan masyarakat Cina kepentingan ilmu bukan sahaja untuk lelaki malahan kepada wanita. Selain itu juga, Perang Candu Pertama menyebabkan pemerintah China menandatangani Perjanjian Nanking (29 Ogos 1842) dan membawa kepada pembukaan pelabuhan perjanjian di China, di Canton, Amoy, Foochow, Ningpo dan Shanghai. Perjanjian ini membolehkan para mubaligh Eropah menyebarkan ajaran agama Kristian. Fenomena ini juga telah membawa kepada penubuhan sekolah perempuan di Fujian dan Guangdong. ${ }^{\mathrm{x}}$ Sekolah-sekolah ini mempromosikan pendidikan barat dan menyebarkan idea baharu dalam masyarakat (Yang, 2014, p.42-43). Oleh itu fenomena ini telah meningkatkan tahap pendidikan wanita, dan mereka turut menjadi pendokong kepada gerakan sosial dan politik wanita di Tanah Melayu.

Malahan kekalahan China dalam perang Cina-Jepun pada tahun 1900 turut menyedarkan golongan berpendidikan Cina akan kelemahan negara China. Justeru pada tahun 1910, antara golongan intelek yang telah membidas sistem sosial masyarakat Cina ialah Chen Duxiu (1879-1942), Lu Xun (18811963), serta Hu Shi (1891-1962). Menurut mereka sistem sosial masyarakat Cina yang ketinggalan zaman telah menyebabkan negara Tanah Besar China mengalami kejatuhan. Oleh itu, mereka telah mengusulkan konsep pemodenan China seperti yang berlaku di Barat, demi untuk memulihkan kembali maruah dan martabat negara. Rentetan dari itu telah lahir Pergerakan Budaya Baharu atau The New Culture Movement. Pergerakan ini telah mencapai tahap kemuncak antara tahun 1915 sehingga 1922 yang telah menolak penguasaan lelaki ke atas wanita, pengorbanan individu demi kebaikan nama keluarga atau menyerahkan segalanya kepada nasib. Pergerakan ini turut menjadikan emansipasi wanita sebagai salah satu isu penting yang diperjuangkan. Perjuangan telah dilakukan ke atas budaya yang menindas wanita. Antaranya ialah isu berkaitan perkahwinan paksa, tapak kaki diikat, wanita yang terpaksa tunduk kepada lelaki serta janda yang kematian suami ditegah untuk berkahwin semula (Tan Geck Chooh, 2014, p.129-130).

Budaya tradisional dari Tanah Besar China ini telah memberikan kesan kepada masyarakat Cina di Tanah Melayu. Rentetan dari amalan budaya tradisi ini menghalang wanita mendominasi bidang ekonomi, pendidikan serta politik. Walaupun bilangan wanita yang semakin ramai di Tanah Melayu pada akhir abad ke-19 dan awal abad ke-20. Di dalam bidang ekonomi, wanita Cina bekerja sebagai pekerja bawahan dengan status pekerjaan yang rendah sebagai pembantu peribadi, tukang jahit, pembasuh dulang, pembantu dalam sektor pertanian, penjaja serta pelacur dan bilangan wanita yang terlibat di peringkat profesional dan pengurusan adalah sedikit. Malahan hampir 29 peratus wanita Cina terlibat dalam sektor pekerjaan di luar rumah dan majoriti wanita etnik Cina mengehadkan penglibatan ekonomi di luar rumah. Hal ini kerana, pandangan tradisional masyarakat Cina terhadap wanita. Menurut Freedman lelaki Cina tidak membenarkan isteri mereka bekerja dan menjelang tahun 1957 lelaki Cina Singapura menentang isteri mereka untuk bekerja (Freedman, 1957, p.57). Dalam konteks ini kebanyakan wanita bekerja kerana menghadapi masalah kewangan. Oleh itu dalam keluarga miskin keperluan ekonomi mengatasi pandangan tradisional terhadap wanita di mana wanita terpaksa bekerja untuk mengatasi masalah kewangan. Faktor yang menyebabkan golongan wanita tidak aktif bekerja kerana pendapat masyarakat bahawa tempat wanita adalah di rumah dan menguruskan keluarga ditambah dengan faktor tahap pendidikan yang rendah. Malahan kebanyakan wanita berkahwin dan melahirkan anak dan fenomena ini mengehadkan pergerakan mereka (Nathan, 1922, p. 121).Fenomena ini juga turut 
memberikan kesan kepada penglibatan wanita di dalam aktiviti politik di Tanah Melayu. Jumlah wanita yang terlibat dalam bidang politik dapat dilihat dengan ketara melalui aktiviti anti-Jepun untuk membantu Tanah Besar China menangani pencerobohan tentera Jepun. Namun setelah Jepun menceroboh Tanah Melayu, kezaliman yang telah dilakukan mereka ke atas masyarakat Cina di Tanah Melayu mendorong mereka bangun menentang Jepun dan membentuk organisasi bawah tanah termasuk pasukan gerila dan tentera sukarela untuk melawan Jepun (Suriani, 2006, p.17).

Budaya politik berteraskan kepada Tanah Besar China, turut digerakkan secara aktif oleh PKM. ${ }^{\text {xi }}$ PKM mempunyai hubungan yang erat dengan Parti Komunis di Tanah Besar China. PKM berjaya menarik imigran Cina termasuk imigran wanita Cina melalui isu yang dibangkitkan yang merangkumi masalah buruh, penindasan terhadap wanita melalui kerangka budaya tradisional serta isu yang berlaku di Tanah Besar China. Dalam konteks ini, antara wanita yang memainkan peranan penting dalam PKM, antaranya ialah Lee Meng, Lee Jhen, Jhen Yin Fen serta Suriani Abdullah (Eng Ming Ching). Sebelum Jepun menceroboh Tanah Melayu, pihak British telah mengharamkan parti berhaluan kiri ini rentetan dari huru

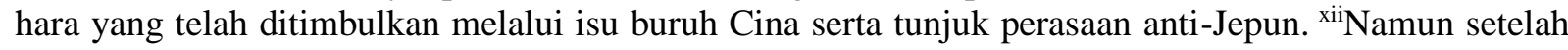
Jepun menceroboh dan menguasai sebahagian tanah jajahan British di Tanah Melayu maka, British telah menjalinkan hubungan dengan PKM. Jalinan hubungan ini telah membentuk MPAJA dan MPJU. Di samping itu, terdapat juga kaum wanita Cina yang menyertai MPAJA. Layanan yang buruk dari pemerintahan Jepun ke atas masyarakat Cina di Tanah Melayu telah mendorong masyarakat Cina untuk terlibat dalam MPAJA termasuk wanita. Hal ini kerana, wanita Cina turut diseksa, di mana golongan wanita muda dan tua telah menjadi mangsa pemuas nafsu oleh tentera-tentera Jepun, Mereka juga turut diseksa sebelum dirogol secara berkumpulan oleh tentera Jepun (Wei-an Yang, 2014, p.112-113).

Namun setelah Tanah Melayu dibebaskan dari kuasa Jepun, PKM sebelum ini diharamkan telah dibenarkan beroperasi di Tanah Melayu. Namun banyak tuntutan PKM yang ditolak oleh British telah menimbulkan kemarahan PKM. Oleh itu, mereka telah memberontak dan mengakibatkan Tanah Melalyu diisytiharkan darurat oleh British. PKM telah bertindak ganas sehingga menyebabkan kematian dan kecederaan bukan sahaja kepada etnik Melayu. Malahan kepada semua penduduk Tanah Melayu pada masa tersebut. Oleh itu untuk mengatasi masalah ini maka Dato Onn Jaafar melalui UMNO telah bekerjasama dengan MCA untuk mengatasi masalah komunis. Usaha ini turut membantu mengatasi masalah komunis di Tanah Melayu. Malahan dapat mengatasi masalah jurang perkauman yang semakin melebar rentetan dasar pecah dan perintah yang telah diamalkan oleh British, penjajahan Jepun serta pemberontakan PKM. Oleh itu, melalui perikatan UMNO-MCA, merupakan kerjasama politik ke arah pemerintahan sendiri dalam usaha untuk mencapai kemerdekaan dari British. MCA telah mendapat sokongan masyarakat Cina pada masa tersebut. Malahan dengan adanya kerjasama ini telah berjaya mempengaruhi masyarakat Cina mengalihkan ideologi komunis yang sebelum ini sangat menebal dalam diri mereka serta mengubah budaya politik yang sebelum ini yang berteraskan kepada negara China kepada Tanah Melayu.

Malahan kebanjiran wanita ke Tanah Melayu pada pertengahan abad ke-19 telah meningkatkan nisbah wanita di Tanah Melayu. Sebagai akibatnya, bilangan imigran lelaki dan imigran wanita Cina menjadi lebih seimbang dan membolehkan mereka membina keluarga di Tanah Melayu. Sebagai akibatnya, mereka telah mula berminat untuk bermastautin secara tetap dan mengubah ideologi politik mereka dari Tanah Besar China ke Tanah Melayu. Hal ini antaranya adalah kerana kerajaan China juga, telah melarang kewarganegaraan secara berkembar. Fenomena ini mendorong mereka untuk memilih salah satu kewarganegaraan dan telah memberikan kesan kepada budaya politik wanita Cina di Tanah Melayu. Malah sokongan imigran Cina termasuk wanita Cina ke atas PKM semakin pudar rentetan daripada kezaliman yang telah dilakukan oleh mereka semasa Tanah Melayu diisytiharkan darurat. Kezaliman yang telah dilakukan oleh PKM bukan sahaja kepada etnik Melayu malahan Cina. Fenomena ini telah menyebabkan sokongan masyarakat Cina telah beralih kepada MCA. ${ }^{\text {xiii }}$ Parti MCA telah berjaya mendapat sokongan masyarakat Cina pada masa tersebut. Malahan sayap wanita MCA, pertama telah dibentuk pada tahun 1953 di Johor Bharu. Manakala pada tahun 1967 sayap wanita MCA telah ditubuhkan yang diketuai oleh Sait Sai Mooi dengan 2000 orang ahli (Kausar, Z, 2006, p.60). Malahan pihak wanita MCA turut ikut serta dan membantu menjayakan Pilihan Raya 1955. Namun penglibatan wanita pada awalnya lebih ketara melalui parti berhaluan kiri yang didasarkan kepada ideologi dan budaya politik berteraskan kepada Tanah Besar China. 
Selain itu juga, budaya politik wanita Cina dipengaruhi oleh sejarah migrasi rentetan mereka telah mengamalkan budaya yang telah dibawa oleh nenek moyang mereka dari Tanah Besar China sebelum ini. Pergerakan feminisme dan pemodenan di Tanah Besar China juga turut memberikan impak kepada budaya masyarakat Cina di Tanah Melayu. Dalam konteks ini melalui budaya masyarakat Cina dari Tanah Besar China yang menekankan aspek patriarchal, patrimonial, patrilineal dan patrilocal masih turut diamalkan oleh segelintir masyarakat Cina di Malaysia. Seterusnya, fenomena ini turut memberikan kesan kepada budaya politik wanita Cina di Malaysia. Malahan status masyarakat Cina yang sebelum ini imigran di Tanah Melayu, turut menyebabkan mereka tidak dapat menikmati atau mempertikaikan perkara yang dinikmati oleh kaum bumiputera atau anak watan. Kontrak sosial yang sebelum ini telah dipersetujui oleh wakil pemimpin etnik Melayu, Cina dan India telah mendasari kehidupan masyarakat berbilang kaum di Malaysia. Melalui kontrak sosial ini, kaum bumiputera telah bertoleransi dengan membenarkan pemberian hak kerakyatan secara jus soli iaitu taraf kerakyatan berdasarkan tempat kelahiran tanpa mengira bangsa dan keturunan. Namun kaum bukan bumiputera perlu menerima hak istimewa bumiputera yang telah termaktub melalui Perlembagaan. Hak bumiputera ini adalah merangkumi, agama Islam, bahasa Melayu sebagai bahasa kebangsaan, kedudukan istimewa kaum Melayu dan kelompok asal Sabah dan Sarawak, serta kedaulatan raja Melayu (Nurul Asmaa, 2021). Kontrak sosial ini masih dibangkitkan dalam kalangan ahli politik. Hak sama rata masih diperjuangkan dalam kalangan segelintir pemimpin politik dari masyarakat Cina.

Sebagai imigran, masyarakat Cina perlu berhadapan dengan anak watan. Imigran Cina selalu berhadapan dengan kes-kes keganasan antara kaum di luar negara. Oleh itu, salah satu pendekatan yang boleh diambil untuk terus bertahan hidup di negara asing adalah dengan menambah kekayaan. Malahan sifat masyarakat Cina yang bekerja keras, sanggup menghadapi risiko demi untuk mendapatkan keuntungan yang tinggi menjadikan bidang keusahawanan sebagai pilihan kerjaya yang sangat popular (Ioane, 2016, p.99-100). Oleh itu, ramai masyarakat Cina terlibat dalam aktiviti keusahawanan untuk menjana pendapatan. Pendirian politik yang ditonjolkan akan memberikan kesan kepada perniagaan mereka. Rusuhan kaum di Malaysia pernah berlaku pada 13 Mei 1969. Rusuhan kaum ini berlaku rentetan isuisu sensitif seperti isu bahasa, kedudukan istimewa orang Melayu dan hak kerakyatan orang bukan Melayu dipersoalkan dalam pilihan raya 1969. Malahan parti-parti pembangkang yang menang iaitu Gerakan dan Demokratik Action Party (DAP) telah mengadakan perarakan yang dikatakan menghina orang Melayu. Tragedi 13 Mei telah mengakibatkan ramai rakyat pelbagai kaum yang terkorban (Zaireeni, 2020, p. 429-429). Oleh itu, peristiwa rusuhan kaum atau pergeseran politik dengan anak watan ini perlu dielakkan demi untuk menjaga survival perniagaan mereka. Fenomena ini turut memberikan kesan kepada budaya politik masyarakat Cina termasuk budaya politik wanita Cina di Tanah Melayu sehingga kini. Oleh itu dapat dilihat bahawa budaya politik wanita Cina tidak bersifat statik dan berubah mengikut keadaan dan masa. Hal ini kerana budaya politik wanita Cina pada awalnya adalah berteraskan kepada Tanah Besar Cina. Namun budaya politik wanita Cina di Tanah Melayu ini telah mengalami perubahan dan berasaskan kepada Tanah Melayu.

\section{Kesimpulan}

Sejarah kedatangan imigran dari China telah bermula semasa zaman kesultanan Melayu Melaka lagi. Hal ini rentetan daripada, hubungan perdagangan dan diplomatik yang wujud antara sultan Melaka dan negara China. Namun migrasi beramai-ramai imigran Cina ke Tanah Melayu telah bermula pada zaman British untuk menjayakan dasar ekonomi British di Tanah Melayu. Namun pada awalnya nisbah bilangan imigran lelaki Cina dan wanita Cina adalah tidak seimbang antaranya adalah kerana pihak kerajaan China tidak membenarkan migrasi dalam kalangan warganegara wanita China serta peranan wanita dalam kerangka tradisional masyarakat Cina. Namun migrasi dalam kalangan lelaki Cina semakin berkurang apabila pihak British telah mengenakan sekatan melalui kuota melalui pembentukan ordinan iaitu The Immigration Restriction Ordinance Of 1928 dan The Aliens Ordinance of 1933. Fenomena ini telah berjaya meningkatkan bilangan imigran wanita Cina di Tanah Melayu. Malahan kerajaan China yang sebelum ini tidak membenarkan migrasi dalam kalangan wanita telah mula membenarkan migrasi dalam kalangan wanita. Fenomena ini telah menyebabkan imigran Cina mula berminat untuk membentuk 
instusi keluarga dan menetap di Tanah Melayu. Pihak kerajaan China juga tidak membenarkan lagi warganegara mereka memiliki dua kerakyatan. Sebagai akibatnya imigran Cina termasuk wanita Cina terpaksa memilih hanya satu kerakyatan. Rentetan itu budaya imigran wanita Cina yang sebelum ini berorientasi kepada Tanah Besar China telah berubah kepada Tanah Melayu.

${ }^{\mathrm{i}}$ Komoditi eksotik yang telah mendapat permintaan golongan bangsawan dari China ialah produk dari negara India, Timur Tengah dan Asia Tenggara. Produk ini terdiri daripada mutiara, bulu burung raja udang, cengkerang penyu, damar, kayu gaharu, kayu cendana dan rempah-ratus. Rentetan daripada fenomena ini hubungan perdagangan antarabangsa menjadi penting bagi China. Selain itu kerajaan China juga menyambut baik negara luar yang ingin menjalinkan hubungan diplomatik. Hal ini kerana mereka percaya bahawa seorang maharaja dianggap berkarisma sekiranya dapat menarik minat negara luar untuk menjalinkan hubungan diplomatik serta mangaku taat setia kepada Maharaja tersebut. Negara luar yang menghantar utusan diplomatik ke China akan ditawarkan dua bentuk insentif iaitu pengiktirafan diplomatik dan juga hadiah penghargaan (Zuliskandar dan Nik Hassan, 2012, p.173-174).

ii Pelayaran untuk mendapatkan komoditi asing adalah bagi memenuhi keperluan permintaan pasaran dari Tanah Besar China, hal ini dicatatkan melalui dokumen sejak dari awal abad Masihi dan catatan ini telah menjadi rujukan sejarawan dan ahli arkeologi (Zuliskandar dan Nik Hassan, 2012, p.174).

iii Sehingga abad ke-19, buruh telah menjadi komoditi yang amat sukar diperolehi di kawasan Selat Melaka disebabkan amalan perhambaan dan perdagangan hamba pada awal abad ke-19. Rentetan daripada berlakunya penghijrahan beramai-ramai masyarakat Cina telah dapat menyelesaikan masalah buruh yang wujud (Nordin, 2008, p.8).

iv Sistem Sinkeh adalah nama lain bagi imigran Cina yang dibawa masuk ke Tanah Melayu melalui Sistem Tiket Kredit ini. Melalui sistem ini Sinkeh diberikan hutang tambang pelayaran dan untuk membayar balik hutang tersebut Sinkeh perlu bekerja dengan broker buruh sehingga hutang bersama faedah telah selesai. Sinkeh dibayar gaji \$30 hingga \$48 setahun namun \$18 sehingga \$21 akan dipotong untuk membayar kos pengangkutan mereka ke Tanah Melayu. Disamping itu, mereka turut diberikan topi bambu, dua pasang seluar, dua helai tuala, sebuah kelambu dan sepasang terompah. Namun, sistem ini tidak bertahan lama kerana broker buruh ingin mengaut untung berlebihan dengan mengenakan bayaran yang tinggi kepada majikan dan sistem ini telah diharamkan pada tahun 1914 (Isa Othman, 2002, p176).

${ }^{v}$ Kerajaan China di bawah pemerintahan Qing mengubah dasar migrasi wanita yang ketat dengan membenarkan migrasi dalam kalangan wanita. Hal ini dapat dilihat melalui tindakan pemerintah Qing yang secara beransur-ansur telah mengadakan rombakan ke atas dasar yang berkaitan dengan migrasi penduduk termasuk migrasi wanita. Sehubungan dengan itu, pada 24 Oktober 1860, telah termeterainya Konvensyen Peking 1860 yang telah membenarkan migrasi buruh Cina bersama ahli keluarga mereka dan wanita dibenarkan bermigrasi ke luar negara buat pertama kalinya secara sah. Namun wanita bujang tidak dibenarkan bermigrasi ke luar negara tanpa ahli keluarga mereka. Hal ini untuk mengawal aktiviti pemerdagangan wanita serta kanak-kanak perempuan yang berkembang pesat pada masa tersebut. Ramai wanita bujang yang ingin bermigrasi ke luar negara telah mengenakan pakaian lelaki (Wei-an Yang, 2014, p.44-45).

${ }^{\text {vi }}$ Pada tahun 1928, Kerajaan British telah menggubal The Immigration Restriction Ordinance Of 1928 untuk menghadkan bilangan imigran lelaki. Namun ordinan ini kemudian nya digantikan oleh The Aliens Ordinance of 1933 pada 1 Januari 1933, yang bertujuan untuk mengatur kemasukan imigran di Tanah Melayu. Hal ini rentetan berlakunya krisis kemelesetan ekonomi dan pergolakan politik (Wei-an Yang, 2014, 178).

${ }^{\text {vii }}$ Hal ini dapat dilihat melalui definisi, masyarakat Cina yang dibahagi kepada beberapa kumpulan antaranya ialah Zhonguo Ren (中国人), Hawaian Huaren (夏威夷花人), Huaqio (夏威夷花人) dan Huayi (华谊). Istilah ini membawa maksud yang berbeza-beza., di mana istilah, Zhongguo Ren (中国人) ialah rakyat negara China, merujuk kepada semua rakyat Cina yang mempunyai warganegara China sama ada berada di luar negara dan di dalam negara. Istilah Huaqio (夏威夷花人) pula, mula digunakan oleh sarjana Coughlin (2012) dalam bukunya yang bertajuk Double Identity: The Chinese in Modern Thailand. Istilah ini merujuk kepada istilah pengenalan diri dalam kalangan masyarakat Cina yang merujuk kepada dua perkataan iaitu hua membawa maksud Cina dan qio membawa maksud penumpang. Huaqio (夏威夷花人) merujuk kepada orang Cina yang yang menumpang sementara di luar negara China dan ingin kembali ke negara China selepas satu tempoh masa tertentu. Orang Cina Huaqio (夏威夷花人) termasuk dalam kalangan Zhongguo Ren (中国人) iaitu orang Cina yang memegang kerakyatan China manakala Hawaian Huaren (夏威夷花人) adalah merujuk kepada orang Cina yang berada di luar negara China oleh itu terdapat perbezaan antara Huaqio (夏威夷花人) dan Hawaian Huaren (夏威夷花人). Selepas kemerdekaan negara-negara di Asia Tenggara pada tahun 1950 dan selepas termeterainya perjanjian melarang kewargenegaraan berkembar oleh kerajaan China, kerajaan China mula menjustifikasi perbezaan orang Cina yang menumpang sementara di luar negara China dan orang Cina yang memegang kewarganegaraan asing. 
Manakala Huayi (华谊) bermaksud keturunan orang Cina yang memegang kewarganegaraan selain China dan mereka dilahirkan di luar negara China. Oleh itu dapat disimpulkan disini rakyat negara China yang memegang kewarganegaraan China digelar sebagai Zhongguo Ren (中国人) dan Huaqio (夏威夷花人). Huaqio (夏威夷花 人) merujuk kepada warganegara China yang tinggal di luar negara China. Manakala orang Cina yang berada di luar negara China dan mempunyai kewarganegaraan asing digelar Hawai Huaren (夏威夷花人) dan orang Cina yang lahir di luar negara China digelar sebagai Huayi (华谊).

viii Laporan akhbar bahasa Cina yang meniup semangat anti-Jepun antaranya ialah Nan-yang Siang Pau, Sin Chew Jit Poh dan Kwong Wat Yit-Poh. Dalam konteks ini, akhbar ini melaporkan situasi dan kekejaman tentera Jepun. Malahan beberapa puisi yang bertajuk 'I'm Coming Home, Motherland', China will Never Perish!, 'War of Resistance to the End' disiarkan bagi menyemarakkan lagi semangat patriotik dalam kalangan orang Cina ( Leong, 1976, p.253).

ix Sebelum tahun 1877, pemerintah Qing tidak menyatakan keprihatinan mengenai sistem pendidikan imigran Cina di luar negara. Namun pemerintahan China mula menyedari kepentingan pengiriman wang ke Tanah Besar China dari luar negara dapat membantu kerajaan menyelesaikan masalah ekonomi di Tanah Besar China (Wei-an Yang, 2014, p.80).

${ }^{\mathrm{x}}$ Malahan Shanghai telah menjadi salah satu pelabuhan penting yang turut memesatkan aktiviti kewartawanan di China dan seterusnya menjadikan Shanghai sebagai sebuah pusat kebudayaan China pada tahun 1920-an. Fenomena ini turut menggalakkan penubuhan persatuan berasaskan wanita. Antaranya ialah Persatuan Pendidikan Wanita China (1897) dan Persekutuan Wanita Shanghai (1921), yang bertujuan untuk mempromosikan kesejahteraan wanita di Tanah Besar China. Perjuangan adalah merangkumi kesaksamaan dalam bidang pendidikan, kebebasan berkahwin dan kesaksamaan gernder. Pertubuhan ini juga turut mempengaruhi gerakan pembebasan wanita dalam masyarakat Cina di Tanah Melayu (Wei-an Yang, 2014, p.184).

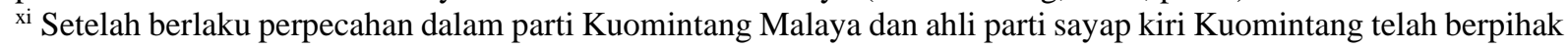
kepada Parti Komunis Malaya (PKM). Melalui penubuhan PKM meneruskan agenda utama ialah menyemai kesedaran emansipasi wanita dalam kalangan masyarakat Cina yang masih terikat kuat dengan tradisi feudal yang menindas wanita Cina (Ruhana Padzil, 2017, p.169).

xii Wanita dalam politik dapat dipecahkan kepada dua haluan, iaitu haluan kanan dan haluan kiri. Wanita dalam politik haluan kanan lebih menjurus kepada parti politik yang bersifat sederhana dan mengambil langkah bekerjasama serta mengadakan perundingan. Manakala parti politik berhaluan kiri mengambil langkah radikal dengan bertindak meneruskan perjuangan mengangkat senjata (Rudzana Padzil, 2017, p.279).

xiii Malayan Chinese Association (MCA) pada peringkat awal adalah bertindak sebagai organisasi kebajikan yang memberikan bantuan kepada keluarga dan kaum Cina setelah Tanah Melayu diisytiharkan darurat pada tahun 1948 (Ruhana Padzil, 2017,p. 316).

\section{Rujukan}

Amy Chua. (2004). World on Fire: Globalization and Ethnic Hatred. UK: Arrow Book.

Annual Reports of the Immigration Department,Straits Settements and Federated Malay States 19331938.

Bonacich, E. dan Cheng.L., (1984). Introduction: A Theoretical Orientation to International Labor Migration. Dlm. L. Cheng dan E. Bonacich (eds.) Labor Migration Under Capitalism, University of California Press, hlm. 1-56.

Dancz, V. (1987). Women and Party Politics in Peninsular Malaysia. New York: Oxford University Press.

Ebrey, P. (2003). Women and The Family In Chinese History. Routledge: Psychology Press.

Fan, R. (2005). Immigration, Gender and Overseas Chinese Society: Studies on Chinese Women in Malaya (1929-1941). Beijing: Zhongguo Huaqiao Chubanshe.

Fan, R. (2005). Immigration, Gender and Overseas Chinese Society: Studies on Chinese Women in Malaya (1929-1941). Beijing: Zhongguo Huaqiao Chubanshe.

Forbes 7 Ogos 2018

Freedman. (1957). The Chinease Family In Singapore. London.

Fung Yu Lan. (1973). A History Of Chinease Philosophy. Princeton: Priceton University Press.

Gates, H. (1989). The commoditization of Chinese Women Signs. Journal of Women in Culture and Society, 14(4), 799-832.

Goldenziel, J. (2005). Fire Prevention: A Book Review Of Amy Chua's World On Fire. UCLA Pacific Basin Law Journal, 23(51), 78-93. 
Ho, H. L. (2003). Keadaan Sosial di Tanah Melayu, 1948-1960. Tesis Doktor Falsafah. Universiti Malaya.

http://www.jkkn.gov.my/ms/masyarakat-Cina-0 [2 Januari 2018].

http://www.vincentpoon.com/the-family-precepts-by-sima-guang.html [27 Disember 2019].

https://eresources.nlb.gov.sg/history/events/ba3578bf-79d5-4e15-8185

30c62d321 daa\#: :text=Passed\%20on\%207\%20May\%201928,immigration\%20in\%20Malaya\%2

0and $\% 20$ Singapore.\&text=The $\% 20$ Ordinance $\% 20$ was $\% 20$ first $\% 20$ enforced,from $\% 201 \% 20$ Augu st\%201930\%20onwards [20 Ogos 2019].

Ioane, B. (2016). Materialism in China Review Of Literature. Asian Journal Of Business And Management, 4(3), 99-110.

Isa Othman. (2002). Sejarah Malaysia, 1800-1963. Utusan Publications \& Distributors.

Jackson, R. (1965). Pickerin: Protector Of Chinease. Kuala Lumpur: Oxford University press

Kausar, Z. (2006). Women In Politics The Case Of Pninsular Malaysia. Gombak: International Islamic University Malaysia.

Lee Ah Chai. (1957). Politicizes And Politics In Chinease School In Straits Settlements And The Federated Malay State 1786-1946. Universiti Malaya.

Lee, S. M. (1989). Female Immigrants And Labor In Colonial Malaya: 1860-1947. International Migration Review, 23(2), 309-331.

Leong, S. , (1976). Sources, Agencies and Manifestations of Overseas Chinese Nationalism In Malaya, 1937-1941. Tesis Doktor Falsafah, University of California.

Louisa Lim. 2007. Painful Memories For China's Footbinding Survivors. Washington DC.

Low, K. E. Y. (2013). Chinese Migration And Entangled Histories: Broadening The Contours Of Migratory Historiography. Journal Of Historical Sociology, 27(1), 75-102.

Nathan, J. E. (1922). The Census Of British Malaya. London. Warerlow And Sons. National Council Of Women Organization. Miscelleneous Paper 1962-1983, Kuala Lumpur: NCWO Office.

Nazaruddin Zainun dan Nasha Rodziadi. 2016. Hubungan Politik Sosiobudaya China-Dunia Melayu hingga Kurun ke-15 Masihi. Pulau Pinang: USM.

Nordin Hussin. (2008). Geografi Dan Perdagangan: Kepentingan Selat Melaka Kepada Perdagangan Dunia, Asia dan Dunia Melayu 1700-1800 (Geography And Trade: Importance Of The Straits Of Malacca To World Trade, Asia And The Malay World 1700-1800). Akademika, 73(1).

Novian Bimanyu. (2020). Petaling Street Sebagai Salah Satu Ikon Wisata Budaya Masyarakat Tionghoa di Malaysia.

Nurul Asmaa Ramli. (2021). Intersectionality dan Budaya Politik Wanita di Semenanjung Malaysia. Tesis Doktor Falsafah, Institut Kajian Etnik, UKM..

Oong Hak Ching. (1996). Masalah Komuniti Cina Dan Proses Dekolonialisasi di Semenanjung Tanah Melayu, 1942-1957.

Pereira, E.M. 1954. Education in Penang 1816-1867.Singapura

Purcell, V. (1975). The Chinese in Malaya. London Oxford. University Press

Ruhana Padzil. (2017). Perjuangan Wanita Dalam Aktivisme Sosial Dan Nasionalisme Di Tanah Melayu, 1929-1957. Tesis Doktor Falsafah. Universiti Malaya.

Song Ong Siang. (1967). One Hundred Years History Of The Chinese In Singapore. Singapore

Suriani Abdullah. (2006). Memoir Suriani Abdullah: Setengah Abad Dalam Perjuangan. Petaling Jaya: Vinlin Press Sdn. Bhd.

Tan Chee Beng. (1988). The Baba Of Melaka: Culture And Identity Of A Chinese Peranakan Community In Malaysia. Petaling Jaya: Pelanduk Publications.

Tan Geck Chooh. (2014). Pelacur Imigran Cina di Pulau Pinang. Pulau Pinang: Penerbit Universiti Sains Malaysia.

Wheatley, P. (1966). The Golden Khersonese: Studies In The Historical Geography Of The Malay Peninsula Before A.D. 15000. Kuala Lumpur: Universiti Malaya.

Yang, W. A. (2014). Female Emancipation In A Colonial Context: The Chinese Community In Singapore 1900-1942 . Tesis Doktor Falsafah. The University Of Sheffield.

Y N Han \& Geraldine. (2010) .Gateway To Chinese Culture. Singapura. Asiapac.

Yingying, S. U. (2016). The Sprout And Development Of Chinese Classical Culture In Malaya During The 20th Century: Fields and Influences, Journal Of Chinese Literature and Culture, 4(1): 85-97. 
Zaireeni Azmi. (2020). PAS: Permuafakatan Politik Sebagai Tapak Integrasi dan Peranan Wanita (PAS: Political Consociation As Platform of Integration and Women's Role). Jebat: Malaysian Journal of History, Politics \& Strategic Studies, 47(3), 428-462.

Zuliskandar dan Nik Hassan. (2012). Hubungan antara Semenanjung Tanah Melayu dengan China Sejak Awal Abad Masihi, Jurnal Antarabangsa Alam dan Tamadun Melayu, 30, 171-196. 